\title{
Thermogravimetric study of a Phase Change Slurry: effect of variable conditions
}

\author{
J. Giro-Paloma ${ }^{1, *}$, R. del Valle-Zermeño ${ }^{1, \mathrm{a}}$, A.I. Fernández ${ }^{1, \mathrm{~b}}$, J.M. Chimenos ${ }^{1, \mathrm{c}}$, J. Formosa ${ }^{1, \mathrm{~d}}$ \\ ${ }^{1}$ Departament de Ciència dels Materials i Enginyeria Metal-lúrgica, Universitat de Barcelona, C/Martí i Franquès, 1-11, 08028,

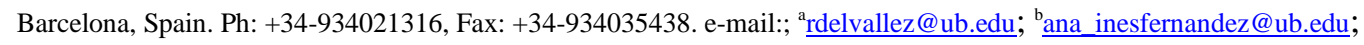

chimenos@ub.edu; ${ }^{\text {ijoanformosa@ub.edu }}$

* Corresponding author: jessicagiro@ub.edu

\begin{abstract}
Microcapsules containing Phase Change Materials (MPCM) are widely used for passive systems in energy storage. When MPCM are mixed with a carrier fluid, Phase Change Slurries (PCS) are used for heat transfer fluids in active systems or heat transport systems. The thermal behavior of PCS can be measured as dry or wet basis, resulting in important differences in weight losses. This study explores the optimum conditions for analyzing the thermal behavior of dried PCS by thermogravimetric analysis (TGA) varying the parameter conditions for obtaining peak temperature and heat flow (latent heat). The factors that were taken into account were the atmosphere of study (air and nitrogen) and the heating rate $\left(0.5,1,5\right.$, and $\left.10^{\circ} \mathrm{C} \cdot \mathrm{min}^{-1}\right)$. The best conditions to determine peak temperature are at $1^{\circ} \mathrm{C} \cdot \mathrm{min}^{-1}$ and in $\mathrm{N}_{2}$ atmosphere, whereas the decomposition fusion/latent heat of the sample is improved at higher heating velocities towards $10^{\circ} \mathrm{C} \cdot \mathrm{min}^{-1}$.
\end{abstract}

Keywords: Phase Change Material, Phase Change Slurry, Thermogravimetrical Analysis.

\section{Introduction}

Energy efficiency in buildings is nowadays an important objective to take into account for energy policy at an international level [1]. Thermal Energy Storage (TES) in buildings includes both the storage as sensible heat and latent heat. The former is performed by changing the temperature of the storage material (when it is heated or when the heat is removed from it) and is directly related with its specific heat capacity. The latter involves the heat release during the phase change of a material and it requires smaller volumes for storing the same amount of energy than the first case [2]. In this sense, Phase Change Materials (PCM) have attracted increasing attention because of their potential use in heat transfer and TES applications due to 
their high energy storage density over a small temperature range [3-5]. PCM are substances with a high heat of fusion that melt and solidify at a certain temperature and are capable of storing and releasing large amounts of energy by absorbing or releasing heat when the material changes from solid to liquid or liquid to solid, respectively [6,7]. These materials are well known in many fields, such as textiles [8], packaging, food [9,10], and buildings [11,12].

The major concern in PCM applications is the fixation of the liquid phase when the PCM is melted for avoiding its leakage and migration. In order to overcome this problem, PCM can be microencapsulated in a polymeric shell of micron sized particles to form Microencapsulated Phase Change Material (MPCM). There are other reasons for encapsulating PCM; in some cases it allows minimizing leaching or volatilization risks [13-15] while preventing agglomeration of the melted paraffin wax when PCM is used for heat storage. Hence, it is important to develop a MPCM shell that is stable enough to support rough conditions [16-19]. For instance, MPCM are used in piping systems when they are mixed with a carrier fluid, commonly water [20] or other organic compounds such as glycerol [21]. These mixtures are called Phase Change Slurries (PCS) and are used for heat transfer fluids in active systems or heat transport systems $[22,23]$. They allow enhancing the energy efficiency while also reducing the amount of thermal fluids [24]. The most employed shell material in a MPCM or PCS is methacrylate [25,26] while $n$-octadecane is widely used as PCM [27,28]. In order to evaluate the capacity of a PCS to withstand hard environments (e.g. pumping conditions), a test rig can be performed in which the sample is subjected to different thermal cycling as described by Gschwander et al. [29].

Thermal properties of PCS can be determined by differential scanning calorimetry (DSC) and thermogravimetric analysis (TGA). The former measures the stored heat while the latter consists of the measurement of the amount and rate of mass loss of a material when it is heated at a given rate under a controlled atmosphere. By this manner, a TGA curve of mass loss $v s$. heating temperature can be obtained. Thus, a material that exhibits loss or gain of mass due to thermal decomposition, oxidation or dehydration, can be analyzed by this technique [30].

Different TGA curves recorded at different heating rates can provide accurate information regarding the mechanism and the kinetics of a polymeric degradation process [31]. Thermal stability has been used in MPCM characterization, such as in Tyagi et al. [32], Ma et al. [33], Qiu et al. [34] studies. Su et al. [35], Zhang et al. [16], and Li et al. [36] evaluated MPCM degradation by using TGA curves. However, in the case of PCS, TGA has been scarcely employed [37]. Taking into account the importance of thermal analysis in characterizing the PCS for properly describing a sample [38], the main goal of this study is to define and explore the best parameters and optimum conditions for analyzing the decomposition of PCS using TGA and DSC. The factors that were taken into account were the state of the sample (liquid and 
air-dried), the atmosphere, and several heating rates. By this manner, a comprehensive characterization and evaluation of the thermal properties may facilitate the understanding of PCS performance.

\section{Experimental procedure}

\subsection{Materials}

The sample under study was Micronal ${ }^{\circledR}$ DS 5045 X from BASF (M). It consists of a suspension made of a highly cross linked methyl methacrylate (MMA) shell and $n$-octadecane as core PCM, with a phase change between 24 and $28{ }^{\circ} \mathrm{C}$. The original sample was tested in liquid state and after being air-dried, MD. Drying took place for 24 hours at room temperature to avoid any thermal degradation. These drying conditions were chosen as reported by GiroPaloma et al. [39].

\subsection{Methods}

\subsubsection{Physico-chemical characterization}

In order to characterize the shape and size after the thermal reliability process of $\mathrm{M}$ sample, Scanning Electron Microscopy (SEM) JEOL JSM-6510 was used. Unlike conventional methods, the preparation of the sample required using $\mathrm{N}_{2}$ as freezing system to solidify the PCS. Hence, a Cryo Unit GATAN accessory (Alto 1000 model) for observing the size and shape of the sample was used. Due to the nature of the sample a conductive carbon coating was also required. The images were obtained by secondary electrons (SE) at $10 \mathrm{kV}$. Moreover, FourierTransformed Infrared spectroscopy (FT-IR) using a FT-IR Spectrum Two ${ }^{\text {TM }}$ from Perkin Elmer (400 - $4000 \mathrm{~cm}^{-1}$ working range) with Attenuated Total Reflectance (ATR) was used to chemically characterized the microcapsules shell.

\subsubsection{Thermal analysis}

Thermogravimetrical analysis (TGA) was performed by means of a SDT Q600 from TA Instruments under $\mathrm{N}_{2}$ and air atmosphere. The scanning rates were $0.5,1,5$ and $10^{\circ} \mathrm{C} \cdot \mathrm{min}^{-1}$ for both atmospheres $\left(50 \mathrm{~mL} \cdot \mathrm{min}^{-1}\right)$ in a temperature range between $20^{\circ} \mathrm{C}\left(\mathrm{T}_{0}\right)$ and $600{ }^{\circ} \mathrm{C}\left(\mathrm{T}_{\mathrm{f}}\right)$. The preparation of the solid sample prior TGA was always performed in the same manner and the amount was kept in a mass range of $10.0 \pm 0.5 \mathrm{mg}$ using alumina $90 \mu \mathrm{L}$ crucibles. The differences observed in the TGA studies were evaluated by assessing the weight loss (\%), the Derivative Thermogravimetry (DTG), and the simultaneous Differential Scanning Calorimetry (s-DSC) signal obtained from the Differential Temperature Analysis (DTA). 
Close to melting interval temperatures of PCM (n-octadecane), a DSC analysis was performed to obtain complementary and more accurate information using a Mettler-Toledo DSC-30 calorimeter. The experimental conditions consisted of using aluminum crucibles of 40 $\mu \mathrm{L}$ in volume in a dry $\mathrm{N}_{2}$ atmosphere with a $50 \mathrm{~mL} \cdot \mathrm{min}^{-1}$ flow rate at $0.5,1,5$, and $10^{\circ} \mathrm{C} \cdot \mathrm{min}^{-1}$.

\section{Results and discussion}

\subsection{Physico-chemical characterization}

Figure 1 shows the size and shape of $\mathrm{M}$ sample after freezing with a cryogenic $\mathrm{N}_{2}$ system. As it shows, microcapsules are uniformly distributed and embedded in the water matrix. The size of the microspheres was lower than $5 \mu \mathrm{m}$. The SEM images for $M$ sample show that microcapsules appear unbroken (Figure 1a). Moreover, some cavities can be observed corresponding to the space provided by some MPCM that was torn during the cryogenic preparation prior the observation.

The MD spectrum obtained by Fourier-Transformed Infrared Spectroscopy (FT-IR) is shown in Figure 2 where the Transmittance (\%) is presented vs. the Wavenumber $\left(\mathrm{cm}^{-1}\right)$.

The different peaks indicate the different functional groups of MD particles. The broadband detected around $3368 \mathrm{~cm}^{-1}$ corresponds to some remaining humidity of the sample. The peaks at 2921 and $2852 \mathrm{~cm}^{-1}$ with $63 \%$ and $73 \%$ of transmittance respectively are attributed to the aliphatic C-H stretching vibration while that at $1726 \mathrm{~cm}^{-1}$ with a $92 \%$ of transmittance is attributed to the ester carbonyl group. Moreover, the peaks at 1466 and $720 \mathrm{~cm}^{-1}$ with 85 and 88 $\%$ abundance, respectively, are associated to the $\mathrm{C}-\mathrm{H}$ bending vibration. Finally, the shorter peak at $1116 \mathrm{~cm}^{-1}$ is due to the $\mathrm{C}-\mathrm{O}$ stretching vibration of the ester group. These results are associated to functional groups of methacrylate forming the shell for both samples. The microcapsules are not broken since the functional groups of $n$-octadecane (PCM) were not detected, as it was already mentioned in SEM observation.

\subsection{Thermal characterization (TGA)}

\subsubsection{Effect of atmosphere}

The effect of the air and $\mathrm{N}_{2}$ atmospheres at different heating rates in TGA performance for the M sample is shown in Figure 3. In all cases, the main difference between both curves is the second weight loss $\left(>250{ }^{\circ} \mathrm{C}\right.$ ) in which the $\mathrm{N}_{2}$ atmosphere showed to enhanced stability. This fact is attributed to the thermo-oxidative degradation of the polymeric shell that takes place in air atmosphere. 
A greater difference in air atmosphere was observed for the MD sample as it can be observed in Figure 4, where the TGA curves are presented at different heating rates. As it was expected, and due to the drying of the sample, a lower decomposition step was observed to what is attributed to water loss $\left(<100{ }^{\circ} \mathrm{C}\right)$. As it can be observed, the main differences for the graphs considering the two different atmospheres, relays in air conditions; but taking into account the effect of different heating rates in the peak temperature in $\mathrm{N}_{2}$ atmosphere, there are some variances. These differences are in the decomposition temperature, which $\mathrm{T}_{\text {peak }}$ values increase at increasing heating rate. In $\mathrm{N}_{2}$ conditions, two decomposition steps could be differentiated (as in Figure 3). However, an interesting behavior was observed in air conditions. At all heating rates, the mass loss step starting over $320^{\circ} \mathrm{C}$ and ending at $370{ }^{\circ} \mathrm{C}$ presented a decrease in temperature and therefore a relapse in the weight loss curve was observed between $350-400$ ${ }^{\circ} \mathrm{C}$. This fact was also observed by Zhang et al. [40,41], although in that study the authors did not attribute it to any particular effect. The relapse step at every heating rate corresponds to an endothermic peak in the same temperature range. There is heat transfer between the crucible and the sample, therefore the heat generated by the endothermic reaction of the sample inside the crucible was attributed to increase the temperature of the thermocouple in the SDT equipment and therefore caused an overestimation of the temperature. Once the compound that is absorbing the heat is consumed, the extra energy produced by the endothermic reaction is stopped and consequently the temperature decreased slightly, producing the relapse in temperature to that of the corresponding compounds remaining in the sample. It is noticeable that this behavior is only observable in air conditions.

In order to focus on the chemical decomposition, it will be used as example Figure $4 d$ where the TGA curves are presented at $0.5^{\circ} \mathrm{C} \cdot \mathrm{min}^{-1}$ in air (solid green line) and $\mathrm{N}_{2}$ (broken dash blue line) atmospheres. When heating paraffinic microcapsules above $100{ }^{\circ} \mathrm{C}$, although the shell is still chemically stable, its mechanical integrity decreases abruptly [39,42]. While it cannot be directly observed in this experiment, the first and second weight losses are attributed to the evaporation/degradation of the PCM and shell, respectively [43].

On the other hand, oxygen increases the rate of degradation, favoring the formation of several oxidized intermediate species during degradation which takes place at substantially lower temperatures than those corresponding to the thermal decomposition in anoxic conditions (i.e. $\mathrm{N}_{2}$ atmosphere). In $\mathrm{N}_{2}$ atmosphere, after the loss of humidity ( 5 wt $\%$ ), two mass losses can be identified according to the literature [18,42]: the first one (35- $40 \mathrm{wt} \%)$ between 200 and $340{ }^{\circ} \mathrm{C}$ is attributed to the decomposition of the paraffin wax, while the subsequent mass loss step (50 - $55 \mathrm{wt} \%)$ is associated to the decomposition of the polymeric shell. Moreover, silica based compound residue $(<5 \mathrm{wt} \%)$ was identified in $\mathrm{N}_{2}$ atmosphere as a result of the pyrolisis conditions. Taking this into consideration, the solely decomposition of paraffin wax 
followed by a structural degradation of the shell in $\mathrm{N}_{2}$ was characterized by two overlapped mass loss steps with a total mass loss of $86.7 \mathrm{wt} . \%$, as confirmed by the TGA/DSC analysis.

\subsubsection{Effect of the sample treatment}

The effects of the sample as slurry (M) and dried slurry (MD) at different heating rates are shown in Figure 5 and Figure 6 for $\mathrm{N}_{2}$ and air atmospheres, respectively. As expected, a great loss of water was observed for the slurry sample (M). The starting temperature of decomposition is earlier for MD for all the cases regarding Figure 5, although this decomposition temperature is more evident at $10^{\circ} \mathrm{C} \cdot \mathrm{min}^{-1}$. According to that, the starting temperature of decomposition of $\mathrm{M}$ sample approaches to that of $\mathrm{MD}$ when heating rate decreases. In this sense, the temperature at which the second step ended slightly decreased as the heating rate decreased. At temperatures above $400{ }^{\circ} \mathrm{C}$ both samples lost their entire weight.

A great number of differences in the shape and onset/offset temperatures of the weight loss curves were observed for the decomposition of the samples (M and MD) in air, as they are shown in Figure 6. Unlike in $\mathrm{N}_{2}$, after the water loss, a decomposition at $\mathrm{T}>200^{\circ} \mathrm{C}$ was observed before a mass loss step at $\mathrm{T}>300^{\circ} \mathrm{C}$. The former is attributed to the paraffin wax decomposition while the second step is regarded to come from the shell. As described in section 3.3.1, the relapse step is again observed around $350^{\circ} \mathrm{C}$, only for the oxidizing atmosphere.

\subsubsection{Effect of heating rate}

Taking into account the differences observed in the decomposition steps taking place at different temperatures in air and $\mathrm{N}_{2}$, the effect of different heating rates was analyzed per atmosphere for both kind of samples (M and MD). Figure 7 presents the corresponding results in air for the M (Figure 7a) and MD (Figure 7b) samples. Both Figures show that increasing the heating rate, greater stability of the sample can be obtained, as the onset/ offset decomposition temperatures are delayed. The relapse step is clearly shown in Figure $7 \mathrm{~b}$.

The profiles of the TGA curves in $\mathrm{N}_{2}$ (Figure 8) are smoother than those obtained in air atmosphere. As in air atmosphere, the effect of increasing the heating rates is clearly observed. This behavior has already been pointed out by Samtani et al. [44].

According to the results presented above, the PCS sample in dried conditions allows to better distinguish between the different mass loss steps. Therefore, a further analysis was made, where DTG and DSC curves were taken into account for elucidating the optimum experimental conditions (e.g. atmosphere and heating rate) in analyzing thermal behavior.

\subsection{Effect of atmosphere in DTG}


DTG curves are commonly employed when analyzing TGA results because they are very sensitive to slight changes and therefore ease the identification of small mass loss steps, especially when these are slightly overlapped $[45,46]$. Thus, the effect of varying conditions in MD decomposition is presented as follows. The effect of air and $\mathrm{N}_{2}$ atmosphere in MD decomposition (solid and broken dash green lines, respectively) in the DTG curves (blue lines, online version) when varying the heating rate $\left(0.5,1,5\right.$, and $\left.10^{\circ} \mathrm{C} \cdot \mathrm{min}^{-1}\right)$ is presented in Figure 9 and Figure 10. The TGA curves are represented in order to facilitate analysis.

As it can be seen in Figure 9a and Figure 9b, the decomposition pattern of TGA and DTG at both heating rates differed for each atmosphere, with the onset $\left(\mathrm{T}_{0}\right)$ and offset $\left(\mathrm{T}_{\mathrm{f}}\right)$ temperatures of the main mass loss steps being in the same range $\left(\mathrm{T}_{0}=175-245{ }^{\circ} \mathrm{C}\right.$ for air, and $\mathrm{T}_{\mathrm{f}}=350-360{ }^{\circ} \mathrm{C}$ for $\mathrm{N}_{2}$ ). However, at $1{ }^{\circ} \mathrm{C} \cdot \mathrm{min}^{-1}$, the anoxic conditions seemed to favor the entire decomposition in the later stages while the remained mass at $0.5^{\circ} \mathrm{C} \cdot \mathrm{min}^{-1}$ can be only attributed to the presence of impurities in the crucible prior analysis. It is worth to notice that at both heating rates all stages of decomposition take place earlier in air. An important effect of delay (of up to $\sim 25^{\circ} \mathrm{C}$ ) at 5 and $10{ }^{\circ} \mathrm{C} \cdot \min ^{-1}$ (Figure 10a and Figure $10 \mathrm{~b}$, respectively) could be observed in $\mathrm{T}_{0}$, especially in an anoxic atmosphere, in which the start of decomposition is observed to take place at greater temperatures with respect an air atmosphere at $5{ }^{\circ} \mathrm{C} \cdot \mathrm{min}^{-1}$ heating rate. This behavior can be regarded to arise from early oxidation reactions of the paraffin and whose occurrence is avoided in anoxic conditions (pyrolysis).

Therefore, for the sake of determining $\mathrm{T}_{0}$ accurately, testing in $\mathrm{N}_{2}$ can be considered the optimum atmosphere that would avoid relapse in the weight loss (thermal inertia) as explained in section 3.3.1 due to oxidizing conditions.

\subsection{Effects on DTA and DSC curves}

The results of Differential Scanning Calorimetry (s-DSC) signal obtained from DTA in the temperature range below $100{ }^{\circ} \mathrm{C}$ obtained from the TGA experimental trials commented above at different heating rates in $\mathrm{N}_{2}$ and air are presented in Figure 11 and Figure 12, respectively. In this temperature range it is possible to observe the endothermic peak corresponding the phase change. By this manner, the effect of different heating rates in the peak temperature $\left(\mathrm{T}_{\text {peak }}\right)$ and heat flow $\left(\mathrm{W} \cdot \mathrm{g}^{-1}\right)$ could be assessed. As it can be seen in Figure 11, as the heating rate increased in an anoxic atmosphere, the $\mathrm{T}_{0}$ and the $\mathrm{T}_{\text {peak }}$ shifted towards higher values along with the widening of the endothermic peak. This broadening effect was very pronounced for 5 and 10 ${ }^{\circ} \mathrm{C} \cdot \mathrm{min}^{-1}$, in which the $\mathrm{T}_{\mathrm{f}}$ extended to up to $80{ }^{\circ} \mathrm{C}$ for the highest heating rate. This shifting pattern effect was also observed in air atmosphere (Figure 12), with an extending $\mathrm{T}_{\mathrm{f}}$ value when increasing the heating rate. 
Table 1 summarizes the results from the DTA analysis made on the MD sample as a function of the type of atmosphere and heating rate. The paraffin wax under different atmospheres at the beginning of the experiment plays an important role for phase change process, and thermo-oxidative degradation is a key point at higher temperatures.

According to these results, the heat flow emitted from the PCS decomposition (and from the energy storage capacity of the PCM) is greater in $\mathrm{N}_{2}$ than air atmospheres, which suggests that the oxidizing or combustion events results less energetic than those from the anoxic conditions. However, $\mathrm{T}_{\text {peak }}$ values were all in the same range regardless the atmosphere, although a decrease as the heating rate decreased was also observed. This effect is a direct consequence of the difference between the time of the furnace to attain a certain temperature (defined by the heating rate) and the thermal inertia of the sample. In practice, this PCS would be employed in situations where heating rates tend to be lower than 10 and $5{ }^{\circ} \mathrm{C} \cdot \mathrm{min}^{-1}$ and hence a phase change enthalpy range of $88.7-108.8 \mathrm{~J} \cdot \mathrm{g}^{-1}$ seems to be the most appropriate reference value when evaluating the thermal storage capacity of this type of PCS. Therefore, low heating rates and hence time-consuming experiments are not necessary when defining $\mathrm{T}_{\text {peak }}$, while a $15-20 \%$ of variation with respect accurately tests has to be assumed when assessing heat flow. The heat associated to the melting of the MD by means of a previous DSC analysis between 10 and $40{ }^{\circ} \mathrm{C}$ at $0.5^{\circ} \mathrm{C} \cdot \mathrm{min}^{-1}$ dynamic heating rate was estimated in $168 \mathrm{~J} \cdot \mathrm{g}^{-1}$ [38], close to that obtained by the TGA/DSC at $10^{\circ} \mathrm{C} \cdot \mathrm{min}^{-1}$ in $\mathrm{N}_{2}\left(124.1 \mathrm{~J} \cdot \mathrm{g}^{-1}\right)$. Thus, in order to accurately determine the heat flow or latent heat of PCS decomposition, experiments at $10^{\circ} \mathrm{C} \cdot \mathrm{min}^{-1}$ seemed to be more suitable.

A DSC comparison of the effect of different heating rates $\left(0.5,1,5\right.$, and $\left.10^{\circ} \mathrm{C} \cdot \mathrm{min}^{-1}\right)$ on DSC curves for MD sample in $\mathrm{N}_{2}$ using another equipment (Mettler-Toledo DSC-30 calorimeter) is shown in Figure 13. As it is depicted, the heating rate increases the $T_{\text {peak }}$ of both endothermic peaks (around 30 and $350{ }^{\circ} \mathrm{C}$ ), although as higher is the temperature more significant is this behavior because of the internal temperature gradient within the sample [47]. Therefore, it is important to establish the optimum conditions to compare all PCS with the same parameters, as the results can change drastically. As it can be observed in the figure, the first peak around $30^{\circ} \mathrm{C}$ corresponds to the phase change of the paraffin wax while that at around 350 ${ }^{\circ} \mathrm{C}$ is attributed to some component of the MPCM shell, which is still under investigation.

\section{Conclusions}

Micronal $^{\circledR}$ DS $5045 \mathrm{X}$ is a microencapsulated phase change material water suspension composed by an acrylic shell and paraffin wax in the core. The SEM observation coupled to a cryogenic $\mathrm{N}_{2}$ system denoted that the material is comprised by non-spherical and non-broken 
capsules lower than $5 \mu \mathrm{m}$. The TGA technique allows measuring several parameters in one experiment, which saves time during characterization. On the one hand, the optimum conditions for determining the $\mathrm{T}_{\text {peak }}$ of this dried material are the heating at $1{ }^{\circ} \mathrm{C} \cdot \mathrm{min}^{-1}$ rate in a $\mathrm{N}_{2}$ atmosphere. In this sense, PCS are expected to be employed in cases with low heating rates. On the other hand, measuring the decomposition heat flow of the MD by means of TGA/DSC is improved at higher heating velocities towards $10^{\circ} \mathrm{C} \cdot \mathrm{min}^{-1}$, as the values obtained were close to that acquired by the more accurate DSC technique. In the light of the results, the experimental conditions and sample state exert a special influence over the results obtained. This study partially determined the best options for obtaining $\mathrm{T}_{\text {peak }}$ and heat flow or latent heat more accurately. Other parameters such as the amount as well as the varying gas flow are currently under research.

\section{Acknowledgments}

The work is partially funded by the Spanish government (ENE2015-64117-C5-2R). The research leading to these results has received funding from the European Union's Seventh Framework Programme (FP7/2007-2013) under grant agreement nº PIRSES-GA-2013-610692 (INNOSTORAGE) and from the European Union's Horizon 2020 research and innovation programme under grant agreement No 657466 (INPATH-TES). Ricardo del Valle Zermeño is grateful to the Government of Catalonia for the research grant (FI-DGR 2014). The authors would like to thank the Catalan Government for the quality accreditation given to their research group DIOPMA (2014 SGR 1543).

\section{References}

[1] L. Pérez-Lombard, J. Ortiz, C. Pout, A review on buildings energy consumption information, Energy Build. 40 (2008) 394-398. doi:10.1016/j.enbuild.2007.03.007.

[2] N. Soares, J.J. Costa, a. R. Gaspar, P. Santos, Review of passive PCM latent heat thermal energy storage systems towards buildings' energy efficiency, Energy Build. 59 (2013) 82-103. doi:10.1016/j.enbuild.2012.12.042.

[3] B. Zalba, J.M. Marín, L.F. Cabeza, H. Mehling, Review on thermal energy storage with phase change: materials, heat transfer analysis and applications, Appl. Therm. Eng. 23 (2003) 251-283. doi:10.1016/S1359-4311(02)00192-8.

[4] A. Sharma, V.V. Tyagi, C.R. Chen, D. Buddhi, Review on thermal energy storage with phase change materials and applications, Renew. Sustain. Energy Rev. 13 (2009) 318345. doi:10.1016/j.rser.2007.10.005.

[5] A.M. Khudhair, M.M. Farid, A review on energy conservation in building applications 
with thermal storage by latent heat using phase change materials, Energy Convers. Manag. 45 (2004) 263-275. doi:10.1016/S0196-8904(03)00131-6.

[6] L.F. Cabeza, C. Castellón, M. Nogués, M. Medrano, R. Leppers, O. Zubillaga, Use of microencapsulated PCM in concrete walls for energy savings, Energy Build. 39 (2007) 113-119. doi:10.1016/j.enbuild.2006.03.030.

[7] Y. Hong, Preparation of Polyethylene-Paraffin Compound as a Form-Stable Solid-Liquid Phase Change Material, Sol. Energy Mater. Sol. Cells. 64 (2000) 37-44. doi:10.1016/S0927-0248(00)00041-6.

[8] P. Sánchez, M.V. Sánchez-Fernandez, A. Romero, J.F. Rodríguez, L. Sánchez-Silva, Development of thermo-regulating textiles using paraffin wax microcapsules, Thermochim. Acta. 498 (2010) 16-21. doi:10.1016/j.tca.2009.09.005.

[9] E. Oró, L. Miró, M.M. Farid, L.F. Cabeza, Thermal analysis of a low temperature storage unit using phase change materials without refrigeration system, Int. J. Refrig. 35 (2012) 1709-1714. doi:doi:10.1016/j.ijrefrig.2012.05.004.

[10] E. Oró, A. De Gracia, L.F. Cabeza, Active phase change material package for thermal protection of ice cream containers, Int. J. Refrig. 36 (2013) 102-109. doi:doi:10.1016/j.ijrefrig.2012.09.011.

[11] R. Baetens, B.P. Jelle, A. Gustavsen, Phase change materials for building applications: A state-of-the-art review, Energy Build. $42 \quad$ (2010) 1361-1368. doi:10.1016/j.enbuild.2010.03.026.

[12] V.V. Tyagi, D. Buddhi, PCM thermal storage in buildings: A state of art, Renew. Sustain. Energy Rev. 11 (2007) 1146-1166. doi:10.1016/j.rser.2005.10.002.

[13] A. Sar1, Form-stable paraffin/high density polyethylene composites as solid-liquid phase change material for thermal energy storage: preparation and thermal properties, Energy Convers. Manag. 45 (2004) 2033-2042. doi:10.1016/j.enconman.2003.10.022.

[14] M. Xiao, B. Feng, K. Gong, Preparation and performance of shape stabilized phase change thermal storage materials with high thermal conductivity, Energy Convers. Manag. 43 (2002) 103-108. doi:10.1016/S0196-8904(01)00010-3.

[15] H. Inaba, P. Tu, Evaluation of thermophysical characteristics on shape-stabilized paraffin as a solid-liquid phase change material, Heat Mass Transf. Und Stoffuebertragung. $32 \quad$ 307-312. http://www.scopus.com/inward/record.url?eid=2-s2.00031124279\&partnerID=tZOtx3y1.

[16] X. Zhang, X. Tao, Y. Kit-lun, X. Wang, Structure and thermal stability of 
microencapsulated phase-change materials, Colloid Polym. Sci. 282 (2004) 330-336. doi:10.1007/s00396-003-0925-y.

[17] Y. Rao, G. Lin, Y. Luo, S. Chen, L. Wang, Preparation and thermal properties of microencapsulated phase change material for enhancing fluid flow heat transfer, Heat Transf. Res. 36 (2007) 28-37. doi:10.1002/htj.20138.

[18] J. Giro-Paloma, C. Barreneche, M. Delgado, M. Martínez, A.I. Fernández, L.F. Cabeza, Physicochemical and thermal study of a MPCM of PMMA shell and paraffin wax as a core, in: Energy Procedia, 2014: pp. 347-354. doi:10.1016/j.egypro.2014.02.040.

[19] J. Giro-Paloma, M. Martínez, L.F. Cabeza, A.I. Fernández, Types, methods, techniques, and applications for Microencapsulated Phase Change Materials (MPCM): A review, Renew. Sustain. Energy Rev. 53 (2016) 1059-1075. doi:10.1016/j.rser.2015.09.040.

[20] S. Baronetto, S. G, G. F, P. M, Numerical Model of a Slurry PCM-Based Solar Thermal Collector, in: Proc. 8th Int. Symp. Heating, Vent. Air Cond. Lect. Notes Electr. Eng., 2014: pp. 13-20. doi:10.1007/978-3-642-39578-9_2.

[21] H. Inaba, Y. Zhang, A. Horibe, N. Haruki, Numerical simulation of natural convection of latent heat phase-change-material microcapsulate slurry packed in a horizontal rectangular enclosure heated from below and cooled from above, Heat Mass Transf. 43 (2007) 459-470. doi:10.1007/s00231-006-0121-y.

[22] P.B. Salunkhe, P.S. Shembekar, A review on effect of phase change material encapsulation on the thermal performance of a system, Renew. Sustain. Energy Rev. 16 (2012) 5603-5616. doi:10.1016/j.rser.2012.05.037.

[23] M. Delgado, A. Lázaro, J. Mazo, B. Zalba, Review on phase change material emulsions and microencapsulated phase change material slurries: Materials, heat transfer studies and applications, Renew. Sustain. Energy Rev. $16 \quad$ (2012) 253-273. http://www.scopus.com/inward/record.url?eid=2-s2.082355173191\&partnerID=40\&md5=9319f1486c5a95749cba4250b81429ca.

[24] Z. Youssef, A. Delahaye, L. Huang, F. Trinquet, L. Fournaison, C. Pollerberg, C. Doetsch, State of the art on phase change material slurries, Energy Convers. Manag. 65 (2013) 120-132. doi:10.1016/j.enconman.2012.07.004.

[25] A. Sarı, C. Alkan, A. Karaipekli, O. Uzun, Microencapsulated n-octacosane as phase change material for thermal energy storage, Sol. Energy. 83 (2009) 1757-1763. doi:10.1016/j.solener.2009.05.008.

[26] A. Sar1, C. Alkan, A. Karaipekli, Preparation, characterization and thermal properties of PMMA/n-heptadecane microcapsules as novel solid-liquid microPCM for thermal 
$\begin{array}{llllll}\text { energy } & \text { storage, } & \text { Appl. } & \text { Energy. } & 87 & \text { (2010) }\end{array}$ doi:10.1016/j.apenergy.2009.10.011.

[27] Y. Fang, S. Kuang, X. Gao, Z. Zhang, Preparation and characterization of novel nanoencapsulated phase change materials, Energy Convers. Manag. 49 (2008) 37043707. doi:10.1016/j.enconman.2008.06.027.

[28] H. Zhang, S. Sun, X. Wang, D. Wu, Fabrication of microencapsulated phase change materials based on n-octadecane core and silica shell through interfacial polycondensation, Colloids Surfaces A Physicochem. Eng. Asp. 389 (2011) 104-117. doi:10.1016/j.colsurfa.2011.08.043.

[29] S. Gschwander, P. Schossig, H. Henning, Micro-encapsulated paraffin in phase-change slurries, Sol. Energy Mater. Sol. Cells. 89 (2005) 307-315. doi:10.1016/j.solmat.2004.12.008.

[30] M.E. Brown, Introduction to Thermal Analysis: Techniques and Applications, Springer Netherlands, 2001. doi:10.1007/0-306-48404-8.

[31] P. Budrugeac, The evaluation of the non-isothermal kinetic parameters of the thermal and thermo-oxidative degradation of polymers and polymeric materials: its use and abuse, Polym. Degrad. Stab. 71 (2000) 185-187. doi:10.1016/S0141-3910(00)00148-8.

[32] V.V. Tyagi, S.C. Kaushik, S.K. Tyagi, T. Akiyama, Development of phase change materials based microencapsulated technology for buildings: A review, Renew. Sustain. Energy Rev. 15 (2011) 1373-1391. doi:10.1016/j.rser.2010.10.006.

[33] Y. Ma, X. Chu, G. Tang, Y. Yao, Adjusting phase change temperature of microcapsules by regulating their core compositions, Mater. Lett. 82 (2012) 39-41. doi:10.1016/j.matlet.2012.05.033.

[34] X. Qiu, W. Li, G. Song, X. Chu, G. Tang, Microencapsulated n-octadecane with different methylmethacrylate-based copolymer shells as phase change materials for thermal energy storage, Energy. 46 (2012) 188-199. doi:10.1016/j.energy.2012.08.037.

[35] J.-F. Su, L.-X. Wang, L. Ren, Synthesis of polyurethane microPCMs containing noctadecane by interfacial polycondensation: Influence of styrene-maleic anhydride as a surfactant, Colloids Surfaces A Physicochem. Eng. Asp. 299 (2007) 268-275. doi:10.1016/j.colsurfa.2006.11.051.

[36] W. Li, X.-X. Zhang, X.-C. Wang, J.-J. Niu, Preparation and characterization of microencapsulated phase change material with low remnant formaldehyde content, Mater. Chem. Phys. 106 (2007) 437-442. doi:10.1016/j.matchemphys.2007.06.030.

[37] P. Zhang, Z.W. Ma, R.Z. Wang, An overview of phase change material slurries: MPCS 
and CHS, Renew. Sustain. Energy Rev. 14 (2010) 598-614. doi:10.1016/j.rser.2009.08.015.

[38] J. Giro-Paloma, M. Delgado, C. Barreneche, M. Martínez, L.F. Cabeza, A.I. Fernández, Thermal Cycle Feasibility of Phase Change Slurry, in: Eurotherm Semin. \#99 Adv. Therm. Energy Storage, Lleida (Spain), 2014.

[39] J. Giro-Paloma, C. Barreneche, M. Martínez, B. Šumiga, A.I. Fernández, L.F. Cabeza, Mechanical response evaluation of microcapsules from different slurries, Renew. Energy. 85 (2016) 732-739. doi:10.1016/j.renene.2015.07.033.

[40] G.H. Zhang, C.Y. Zhao, Thermal property investigation of aqueous suspensions of microencapsulated phase change material and carbon nanotubes as a novel heat transfer fluid, Renew. Energy. 60 (2013) 433-438. doi:10.1016/j.renene.2013.05.041.

[41] G.H. Zhang, C.-Y. Zhao, Thermal and rheological properties of microencapsulated phase change materials, Renew. Energy. $36 \quad$ (2011) 2959-2966. doi:doi:10.1016/j.renene.2011.04.002.

[42] J. Giro-Paloma, G. Oncins, C. Barreneche, M. Martínez, A.I. Fernández, L.F. Cabeza, Physico-chemical and mechanical properties of microencapsulated phase change material, Appl. Energy. 109 (2013) 441-448. doi:10.1016/j.apenergy.2012.11.007.

[43] J. Giro Paloma, Characterization of polymers and Microencapsulated Phase Change Materials used for Thermal Energy Storage in buildings, Universitat de Barcelona, 2015.

[44] M. Samtani, D. Dollimore, K.S. Alexander, Comparison of dolomite decomposition kinetics with related carbonates and the effect of procedural variables on its kinetic parameters, Thermochim. Acta. 392-393 (2002) 135-145. doi:http://dx.doi.org/10.1016/S0040-6031(02)00094-1.

[45] M.E. Brown, Introduction of Thermal Analysis. Techniques and Applications, 2001.

[46] R. del Valle-Zermeño, J.M. Chimenos, J. Formosa, A.I. Fernández, Hydration of a lowgrade magnesium oxide. Lab-scale study, J. Chem. Technol. Biotechnol. 87 (2012) 1702-1708. http://www.scopus.com/inward/record.url?eid=2-s2.084869171708\&partnerID=40\&md5=02e49183f4a946b751e086a7c2fdca7d.

[47] E. Günther, S. Hiebler, H. Mehling, R. Redlich, Enthalpy of Phase Change Materials as a Function of Temperature: Required Accuracy and Suitable Measurement Methods, Int. J. Thermophys. 30 (2009) 1257-1269. doi:10.1007/s10765-009-0641-z. 


\section{Figure Captions:}

Figure 1.- SEM micrographies for M sample, Micronal ${ }^{\circledR}$ DS 5045 X (magnification: x 2200 left and $\mathrm{x} 5500$ right).

Figure 2. FT-IR spectra of MD.

Figure 3.- Comparison of TGA curves for M sample (Micronal ${ }^{\circledR}$ DS $5045 \mathrm{X}$ slurry) in air and $\mathrm{N}_{2}$ at different heating rates. a) $10{ }^{\circ} \mathrm{C} \cdot \mathrm{min}^{-1}$ in air and $\mathrm{N}_{2}$; b) $5{ }^{\circ} \mathrm{C} \cdot \min ^{-1}$ in air and $\mathrm{N}_{2}$; c) 1 ${ }^{\circ} \mathrm{C} \cdot \min ^{-1}$ in air and $\mathrm{N}_{2} ;$ d) $0.5^{\circ} \mathrm{C} \cdot \mathrm{min}^{-1}$ in air and $\mathrm{N}_{2}$.

Figure 4.- Comparison of TGA curves for MD sample (dried Micronal ${ }^{\circledR}$ DS $5045 \mathrm{X}$ slurry) in air and $\mathrm{N}_{2}$ atmospheres at different heating rates. a) $10^{\circ} \mathrm{C} \cdot \min ^{-1}$; b) $5^{\circ} \mathrm{C} \cdot \min ^{-1}$; c) $1{ }^{\circ} \mathrm{C} \cdot \min ^{-1}$; d) $0.5^{\circ} \mathrm{C} \cdot \mathrm{min}^{-1}$.

Figure 5.- TGA curves of $\mathrm{M}$ and $\mathrm{MD}$ in $\mathrm{N}_{2}$ at different heating rates, a) $10^{\circ} \mathrm{C} \cdot \mathrm{min}^{-1}$; b) 5 ${ }^{\circ} \mathrm{C} \cdot \min ^{-1}$; c) $1{ }^{\circ} \mathrm{C} \cdot \min ^{-1}$; d) $0.5^{\circ} \mathrm{C} \cdot \min ^{-1}$.

Figure 6.- TGA curves in air atmosphere at different heating rates for $\mathrm{M}$ and $\mathrm{MD}$ a) $10^{\circ} \mathrm{C} \cdot \mathrm{min}^{-1}$; b) $5^{\circ} \mathrm{C} \cdot \min ^{-1}$; c) $1^{\circ} \mathrm{C} \cdot \min ^{-1}$; d) $0.5^{\circ} \mathrm{C} \cdot \min ^{-1}$.

Figure 7.- TGA curves in air atmosphere at different heating rates for a) M sample (Micronal ${ }^{\circledR}$ DS 5045 X slurry) and b) MD sample (dried Micronal ${ }^{\circledR}$ DS 5045 X slurry). Heating rates: 10 ${ }^{\circ} \mathrm{C} \cdot \min ^{-1}, 5^{\circ} \mathrm{C} \cdot \min ^{-1}, 1^{\circ} \mathrm{C} \cdot \min ^{-1}$, and $0.5^{\circ} \mathrm{C} \cdot \min ^{-1}$.

Figure 8.- TGA curves in $\mathrm{N}_{2}$ atmosphere at different heating rates for a) $\mathrm{M}$ sample (Micronal ${ }^{\circledR}$ DS 5045 X slurry) and b) MD sample (dried Micronal ${ }^{\circledR}$ DS 5045 X slurry). Heating rates: 10 ${ }^{\circ} \mathrm{C} \cdot \min ^{-1}, 5^{\circ} \mathrm{C} \cdot \min ^{-1}, 1^{\circ} \mathrm{C} \cdot \min ^{-1}$, and $0.5^{\circ} \mathrm{C} \cdot \min ^{-1}$.

Figure 9. TGA and DTG results for MD sample in both atmospheres at a) $0.5^{\circ} \mathrm{C} \cdot \min ^{-1}$ and b) 1 ${ }^{\circ} \mathrm{C} \cdot \min ^{-1}$.

Figure 10. TGA and DTG results for MD sample in both atmospheres at a) $5^{\circ} \mathrm{C} \cdot \min ^{-1}$ and b) 10 ${ }^{\circ} \mathrm{C} \cdot \min ^{-1}$.

Figure 11. DTA curves at different heating rates $\left(0.5,1,5\right.$, and $\left.10^{\circ} \mathrm{C} \cdot \mathrm{min}^{-1}\right)$ for the MD sample in $\mathrm{N}_{2}$ atmosphere.

Figure 12. DTA curves at different heating rates $\left(0.5,1,5\right.$, and $\left.10^{\circ} \mathrm{C} \cdot \mathrm{min}^{-1}\right)$ for the MD sample in air atmosphere.

Figure 13.-DSC results at $0.5,1,5$, and $10^{\circ} \mathrm{C} \cdot \mathrm{min}^{-1}$ from the dried samples in $\mathrm{N}_{2}$ atmosphere. 
Table Captions:

Table 1. DSC results for the MD sample. 

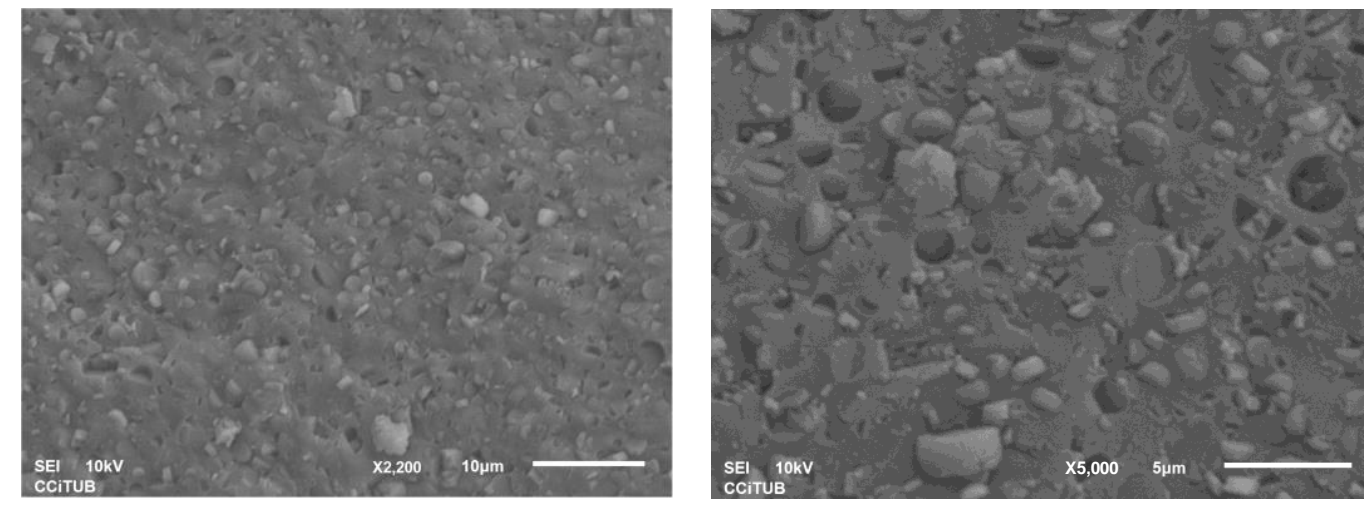

Figure 1

J. Giro-Paloma et al.

2016

Thermogravimetric study of a Phase Change Slurry: effect of variable conditions 


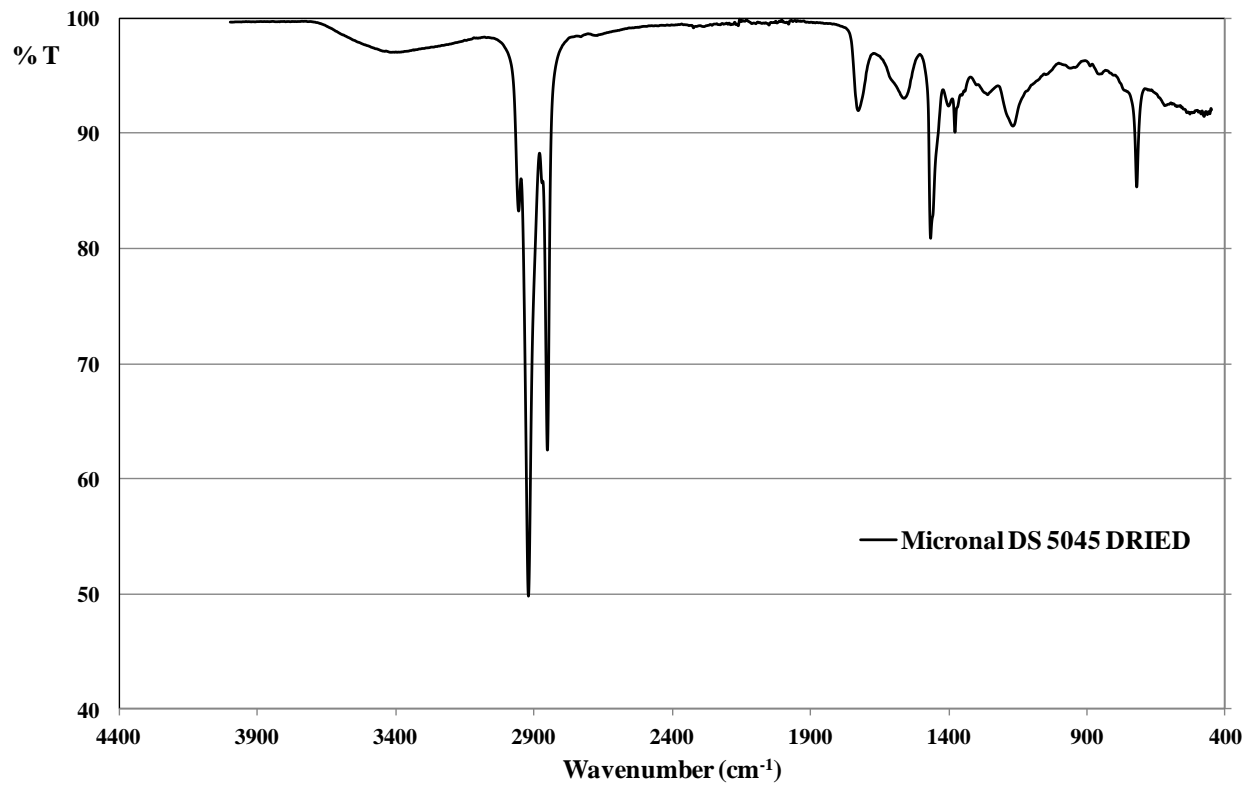

Figure 2

J. Giro-Paloma et al.

2016

Thermogravimetric study of a Phase Change Slurry: effect of variable conditions 


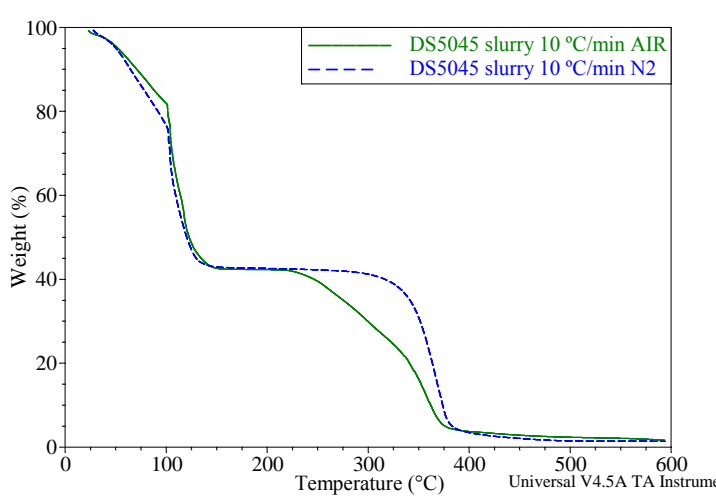

a)

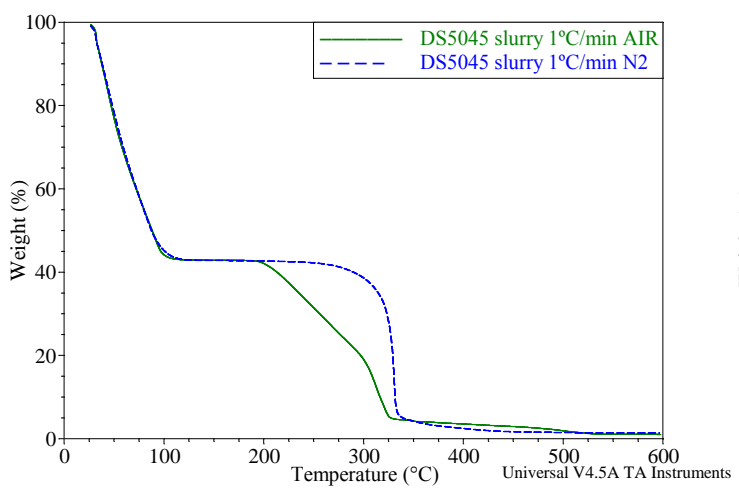

c)

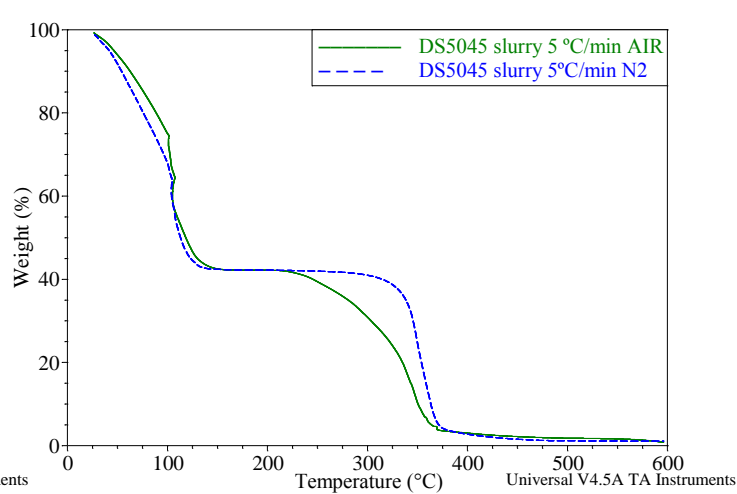

b)

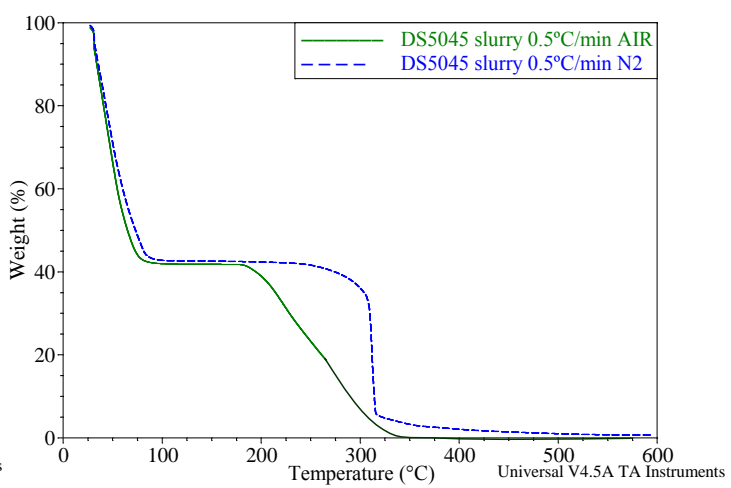

d)

Figure 3

J. Giro-Paloma et al.

2016

Thermogravimetric study of a Phase Change Slurry: effect of variable conditions 


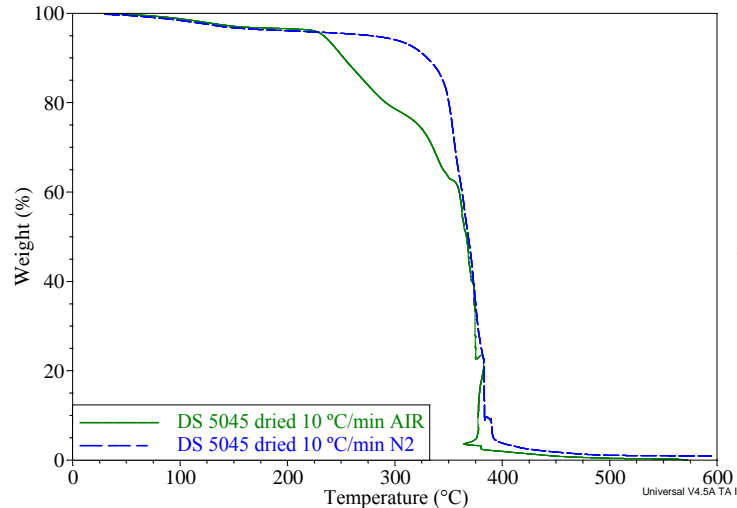

a)

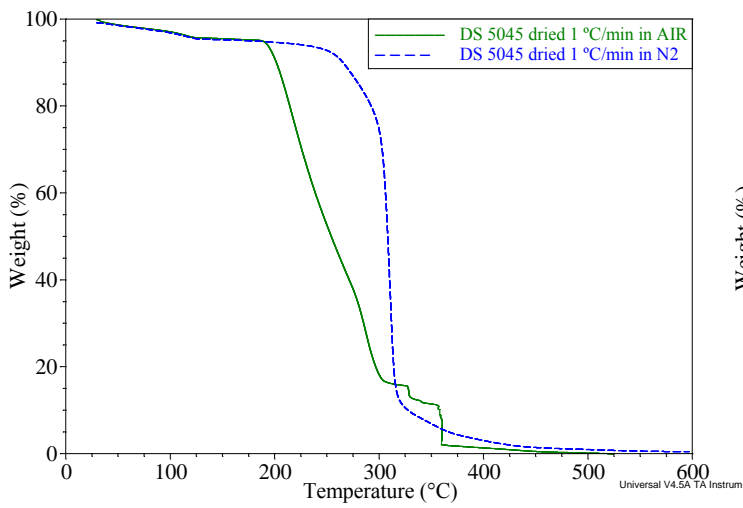

c)

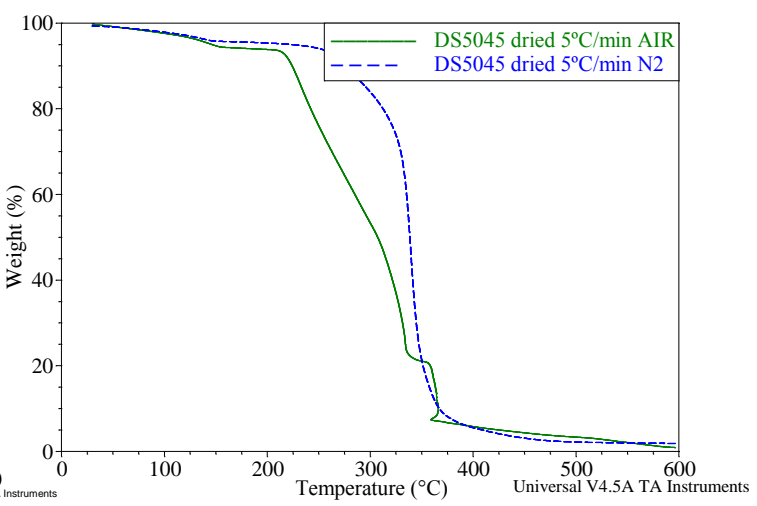

b)

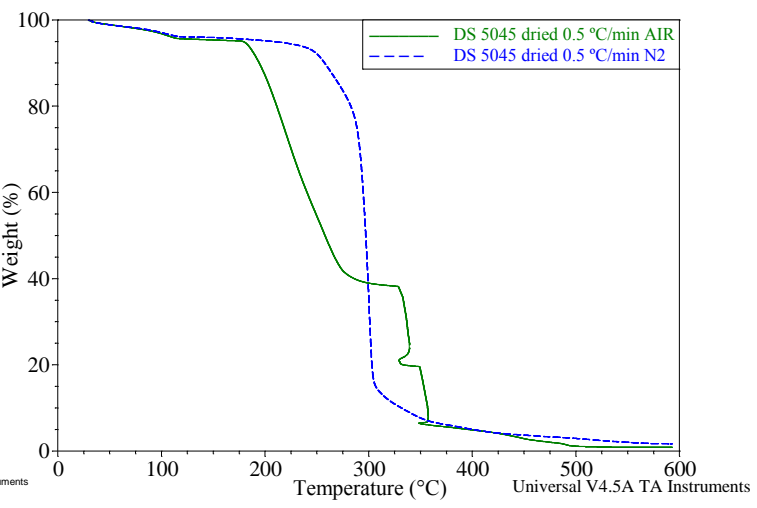

d)

Figure 4

J. Giro-Paloma et al.

2016

Thermogravimetric study of a Phase Change Slurry: effect of variable conditions 


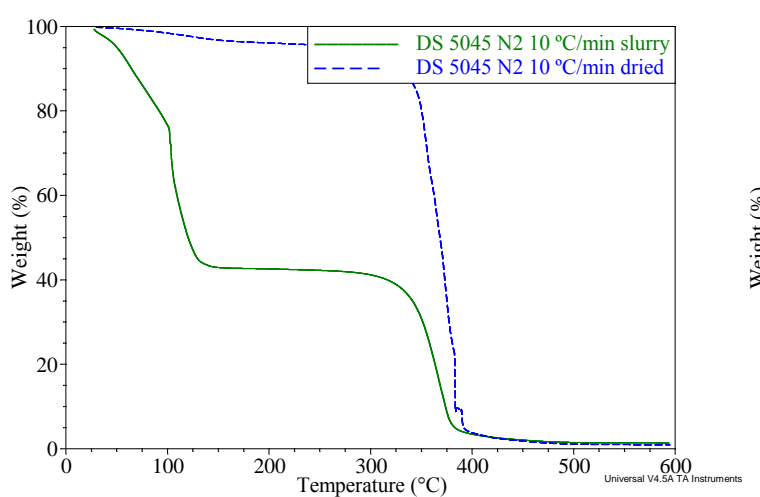

a)

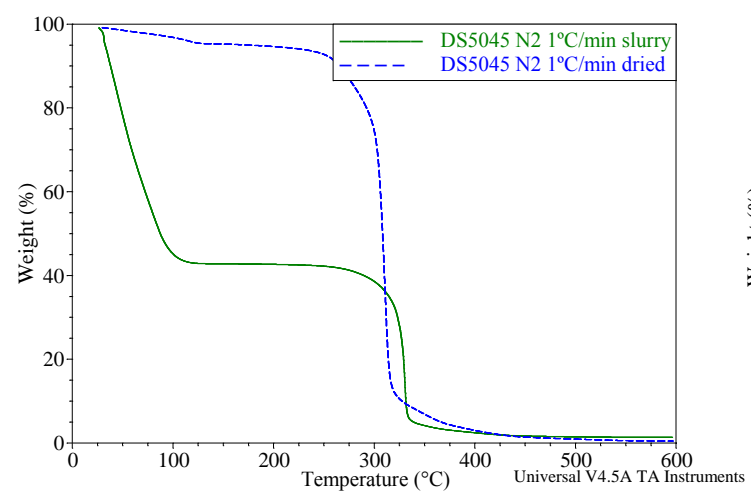

c)

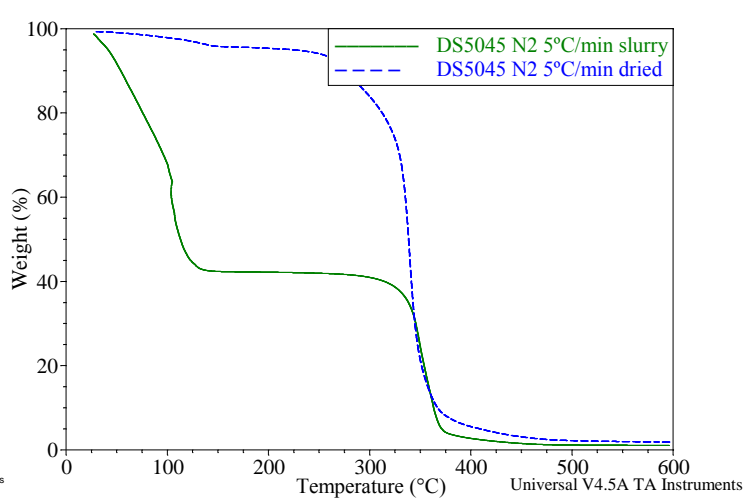

b)

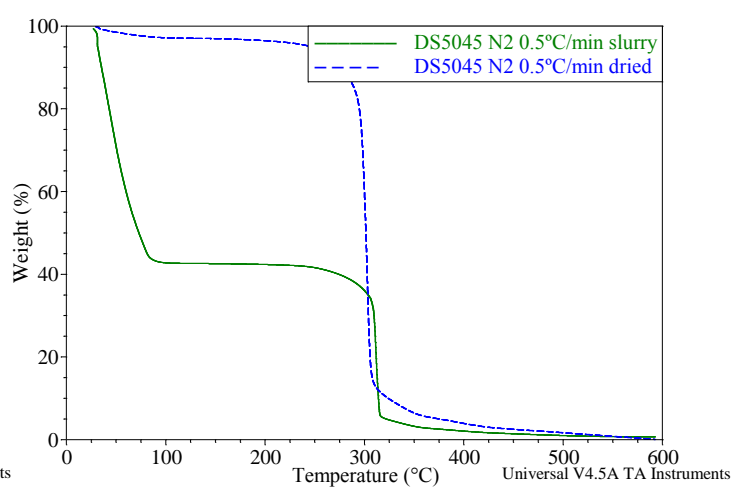

d)

Figure 5

J. Giro-Paloma et al.

2016

Thermogravimetric study of a Phase Change Slurry: effect of variable conditions 

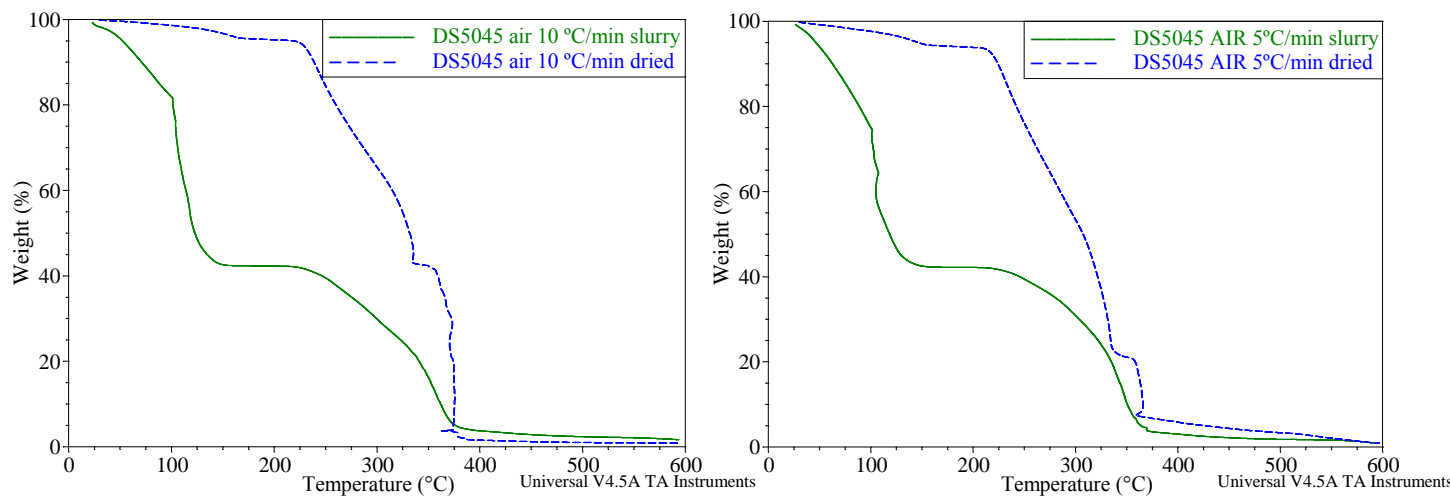

a)

b)
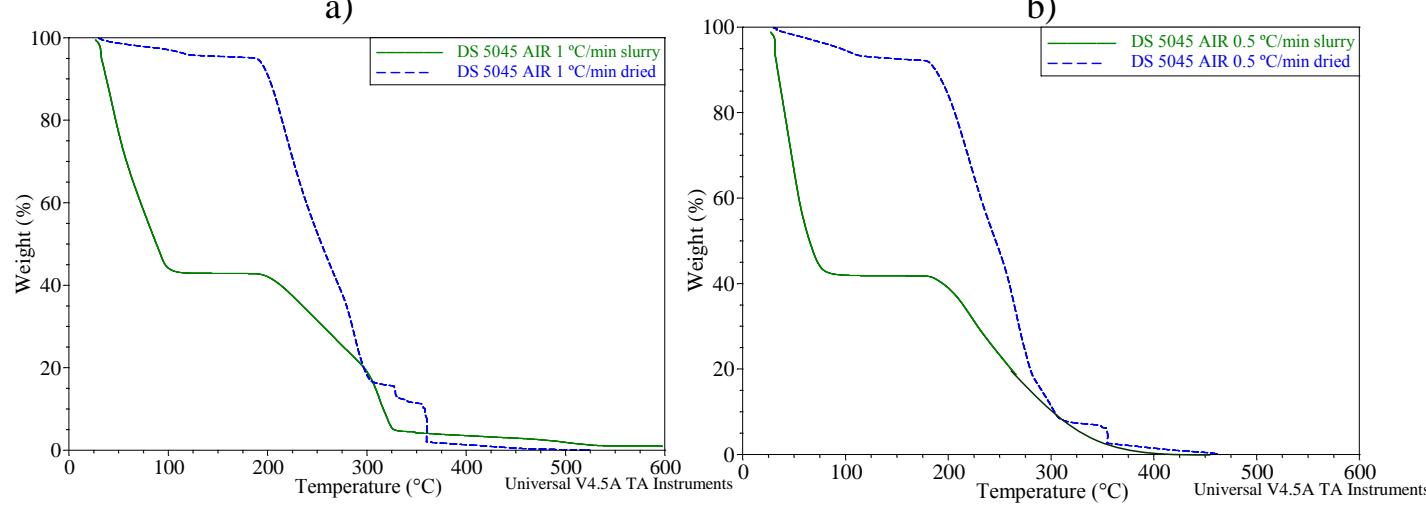

c)

d)

Figure 6

J. Giro-Paloma et al.

2016

Thermogravimetric study of a Phase Change Slurry: effect of variable conditions 


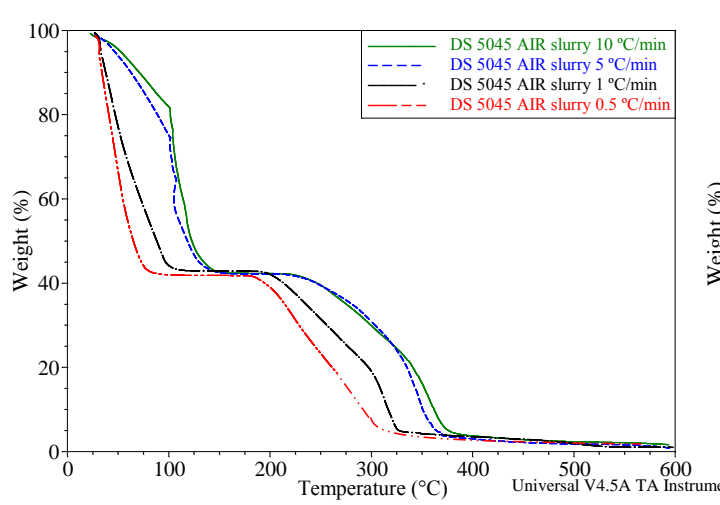

a)

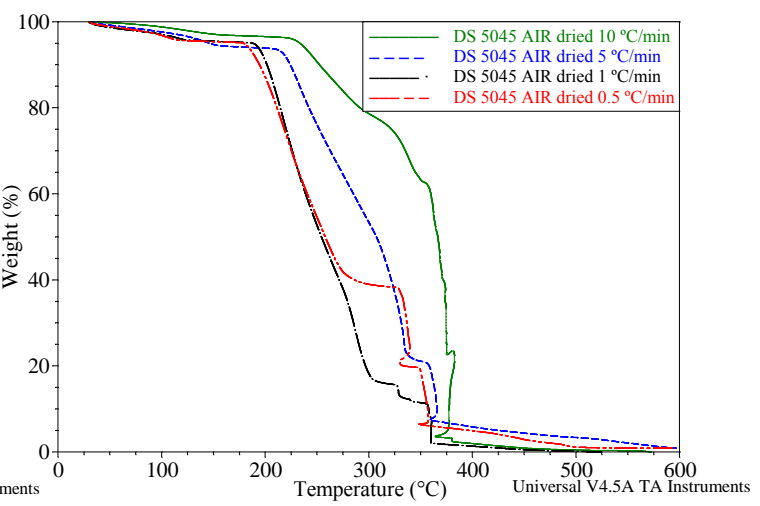

b)

Figure 7

J. Giro-Paloma et al.

2016

Thermogravimetric study of a Phase Change Slurry: effect of variable conditions 


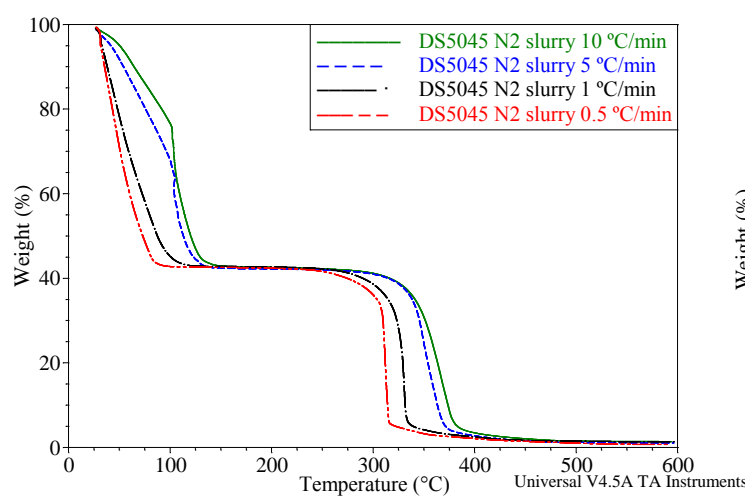

a)

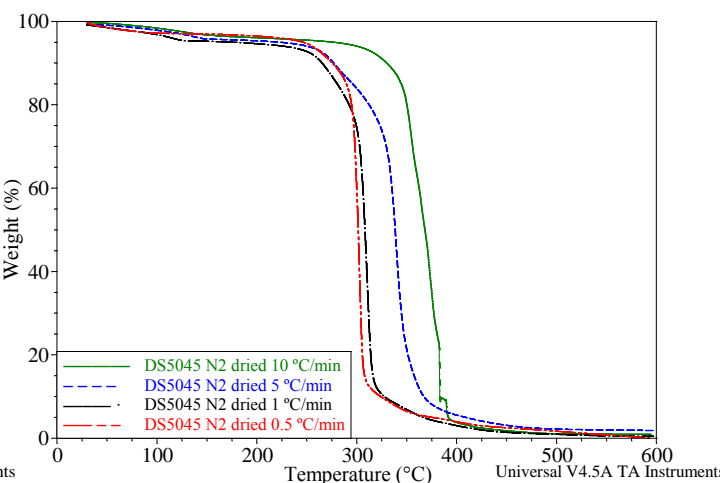

b)

Figure 8

J. Giro-Paloma et al.

2016

Thermogravimetric study of a Phase Change Slurry: effect of variable conditions 


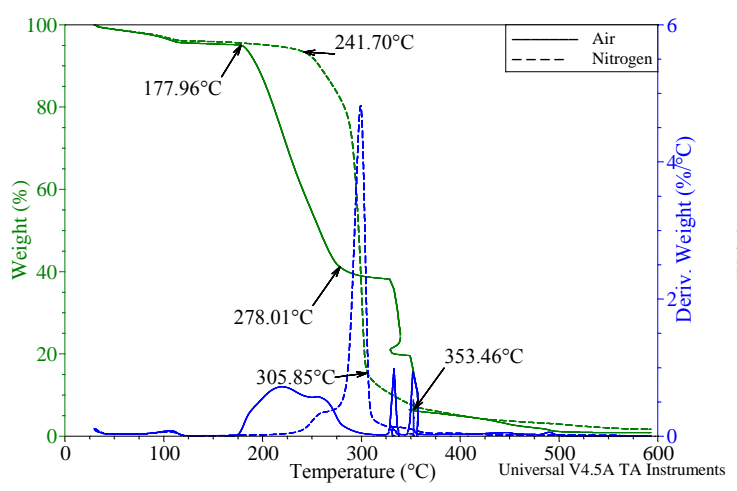

a)

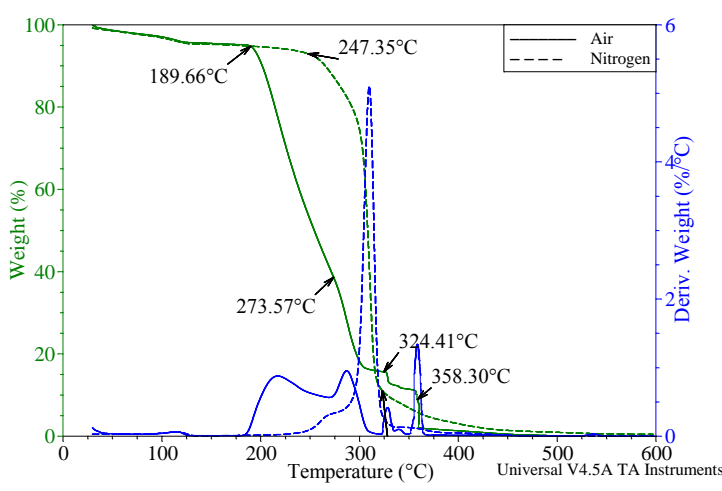

b)

Figure 9

J. Giro-Paloma et al.

2016

Thermogravimetric study of a Phase Change Slurry: effect of variable conditions 


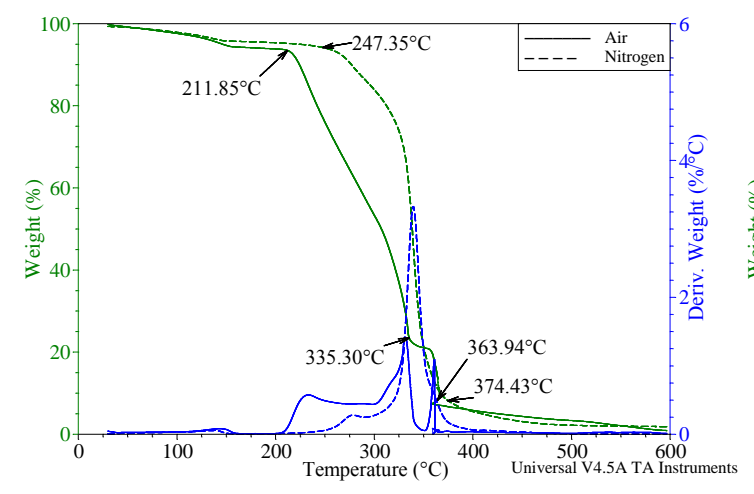

a)

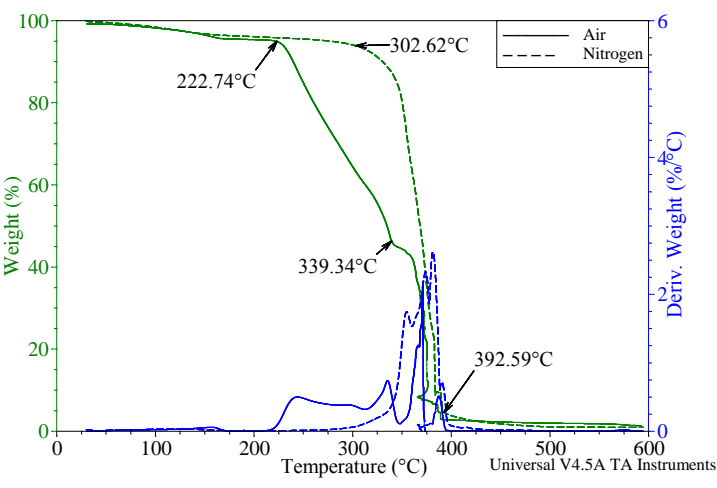

b)

Figure 10

J. Giro-Paloma et al.

2016

Thermogravimetric study of a Phase Change Slurry: effect of variable conditions 


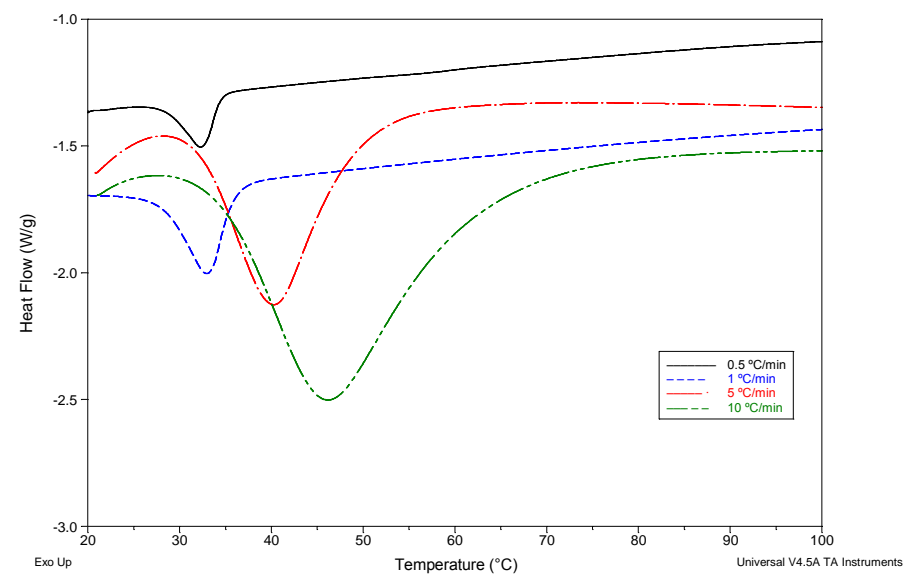

Figure 11

J. Giro-Paloma et al.

2016

Thermogravimetric study of a Phase Change Slurry: effect of variable conditions 


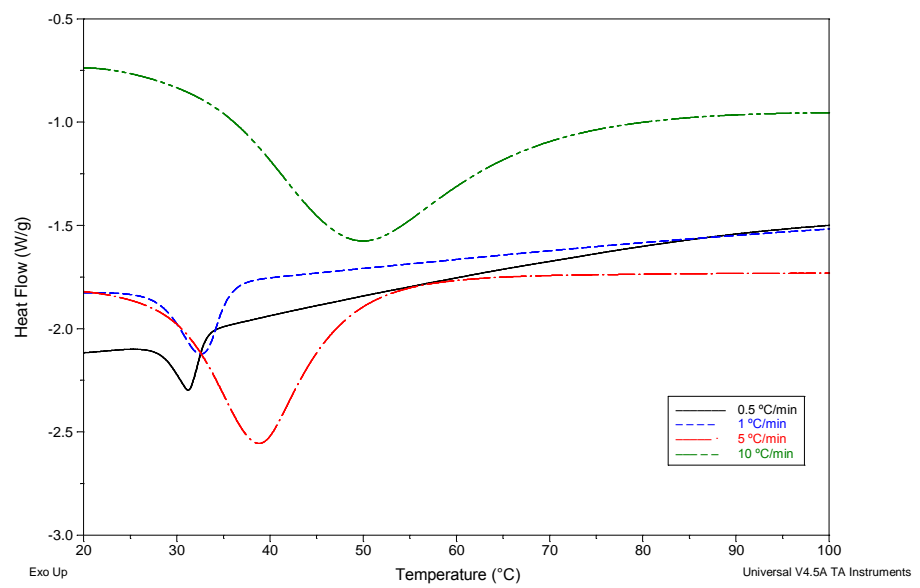

Figure 12

J. Giro-Paloma et al.

2016

Thermogravimetric study of a Phase Change Slurry: effect of variable conditions 


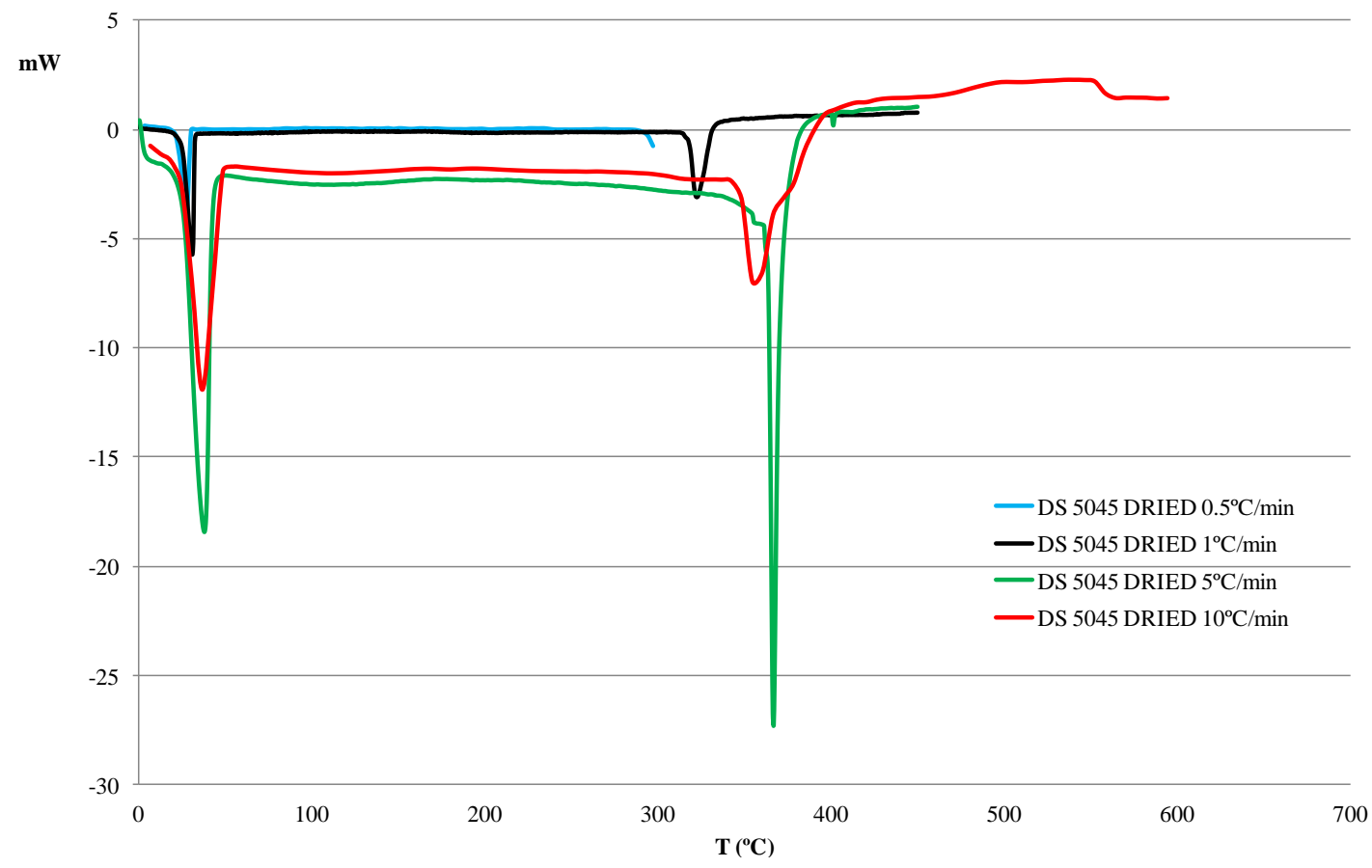

Figure 13

J. Giro-Paloma et al.

2016

Thermogravimetric study of a Phase Change Slurry: effect of variable conditions 
Table 1

\begin{tabular}{|c|c|c|c|c|}
\hline \multirow[b]{2}{*}{$\begin{array}{l}\text { Heating rate } \\
\left({ }^{\circ} \mathbf{C} \cdot \mathbf{m i n}^{-1}\right)\end{array}$} & \multicolumn{2}{|c|}{ Nitrogen atmosphere } & \multicolumn{2}{|c|}{ Air atmosphere } \\
\hline & $\begin{array}{c}\text { Heat flow/ } \\
\text { Latent heat } \\
\left(\mathrm{J} \cdot \mathrm{g}^{-1}\right)\end{array}$ & $\mathbf{T}_{\text {peak }}\left({ }^{\circ} \mathbf{C}\right)$ & $\begin{array}{c}\text { Heat flow/ } \\
\text { Latent heat } \\
\left(\mathrm{J} \cdot \mathrm{g}^{-1}\right)\end{array}$ & $\mathrm{T}_{\text {peak }}\left({ }^{\circ} \mathrm{C}\right)$ \\
\hline$\overline{0.5}$ & 108.5 & 32.3 & 88.7 & 32.3 \\
\hline 1.0 & 108.8 & 32.6 & 89.9 & 33.0 \\
\hline 5.0 & 121.2 & 38.8 & 92.8 & 40.3 \\
\hline 10.0 & 124.1 & 49.7 & 100.2 & 46.2 \\
\hline
\end{tabular}

J. Giro-Paloma et al.

2016

Thermogravimetric study of a Phase Change Slurry: effect of variable conditions 